\title{
The Study on the Removal of Ultrafine Particles
}

\author{
Daolai $\mathrm{CHENG}^{1, \mathrm{a}}$, Meng $\mathrm{CAl}^{2, \mathrm{~b} *}$, Fang $\mathrm{ZHAO}^{2, \mathrm{c}}, \mathrm{Huimin}^{\mathrm{H}} \mathrm{Hu}^{2, \mathrm{~d}}$, Junfeng $\mathrm{YAO}^{2, \mathrm{e}}$
}

1. Department of Science \& Technology, Shanghai Institute of Technology, Shanghai 201418, China;

2. Department of Energy\& Power Engineering, Shanghai Institute of Technology, Shanghai 201418, China;

a email: Daolai Cheng@163.com; b email: 616568394@qq.com; c email: zhfnet77@163.com;

d email: huhuimin1988@163.com; e email: 1184996184@qq.com

Keywords: ultrafine particles, seed particles, ultrasonic atomization, acoustic agglomeration

Abstract: Ultrafine particles PM2.5 produced during combustion is the main source of environment pollution and has raised the widespread concern around the world. There are several studies about acoustic agglomeration currently, but its removal efficiency is not high, so the scholars have proposed to join the seed particles on the basis of acoustic agglomeration, to increase the removal efficiency. In this paper, we propose to join seed particles with ultrasonic atomization and analyze the advantages of using ultrasonic atomization. This is another effective method to improve the removal efficiency.

\section{Introduction}

PM2.5, referring to the aerodynamic particles less than 2.5 microns in diameter caused by the combustion of coal, oil, natural gas and biomass, etc. has become the main source of environmental pollution in China for the present, and the way to control it has also aroused the world concern. Instead of using regular dust remover, pretreatment method has been widely adopted for the removal difficulty among which acoustic agglomeration gets the most attention. However, ultrasonic atomization for seed particles become more and more significant on account of the low efficiency, noise as well as other pollutions of acoustic agglomeration. This paper not only analyzes the development status and existing problems of ultrasonic atomization, but also puts forward the way to integrate ultrasonic atomization to acoustic agglomeration and its benefits, which points out the future development trend.

\section{The research on the acoustic agglomeration for ultrafine particles}

\section{The principle of the acoustic agglomeration}

The process of the collision between particles and particles generated by sound waves to form larger particles is referred as acoustic agglomeration. Sound waves with acoustic energy produce various effects, such as amplitude, speed and phase, on particles with different sizes, resulting in a relative motion and also contributing to the collision. What's more, the larger the particle is, the bigger the effect is. Accordingly, small particles become less and less while large particles are on the contrary, thus the conventional dust remover can make a difference. 


\section{The study status of acoustic agglomeration}

It has been more than one hundred years since the birth of acoustic agglomeration. As early as 1886, Willaim Ostwld has proposed the idea of using sound field to agglomeration fine particles [1]. In 1960s, Mednikov [2] summarized the early studies of acoustic agglomeration. And in 1970s, scholars began to pay more attention on it due to the improvement of environmental standards and studies in Acoustic Institute in Madrid, Spain and the University of Pennsylvania in United States are the most prominent.

The similar research has been done in domestic universities such as Southeast University, Zhejiang University, Tsinghua University, Beijing Institute of Technology, Qingdao University of Science and Technology, North China Electric Power University, Huazhong University of Science and Technology, etc [3, 4]. Funded by 973 program, Southeast University has made a deep research on the dynamic characteristic and the agglomeration effect of inhalable particle of combustion source under the influence of external sound field and had achieved many innovations. All the studies will be listed in the following Table 1.

Table 1: the important studies

\begin{tabular}{|c|c|c|}
\hline Time & Author & Results \\
\hline 2003 & Gallego-Juarez [5] & $\begin{array}{l}\text { used four } 400 \mathrm{~W} \text { power ultrasonic transducers as the sound source. The experimental results show that the } \\
\text { effect of the acoustic agglomeration of } 10 \mathrm{kHZ} \text { was equivalent to } 20 \mathrm{kHz} \text {, and the number of smoke } \\
\text { particle concentration after treatment decreased by } 40 \% \text {. }\end{array}$ \\
\hline 2003 & Riera-Franco [6] & $\begin{array}{l}\text { used the same sound source, and processed the exhaust gas of the diesel engine, and found that the effect } \\
\text { of } 20 \mathrm{kHz} \text { is better than } 10 \mathrm{kHz} \text {, also found that if you increase the volume fraction in the flue gas of } 6 \% \\
\text { water vapor, can improve the agglomeration effect. }\end{array}$ \\
\hline 1979 & Shaw [7] & $\begin{array}{l}\text { used the polystyrene and dioctyl phthalate based on electric horn }(1000-3000 \mathrm{~Hz}) \text { with sound intensity of } \\
145 \mathrm{~dB} \text { as sound source. It turned out that the frequency has little influence on the acoustic agglomeration } \\
\text { if the diameter of the particle is shorter than } 0.5 \mu \mathrm{m} \text { and the frequency lower than } 10 \mathrm{KHz} \text {. }\end{array}$ \\
\hline 1983 & Cheng[8] & $\begin{array}{l}\text { studied the agglomeration of chloride particles in the traveling wave field, with the frequency of } \\
0.6-3 \mathrm{kHz} \text {, and the sound pressure of } 145-150 \mathrm{~dB} \text {, and it was found that the frequency had a great influence } \\
\text { on the agglomeration efficiency, especially in } 3 \mathrm{kHz} \text {. }\end{array}$ \\
\hline 1984 & Tiwary[9] & $\begin{array}{l}\text { studied ash-laden gas with the sound intensity of } 170 \mathrm{~dB} \text { and frequency of } 1000-3500 \mathrm{~Hz} \text { by acoustic } \\
\text { agglomeration. And the best sound intensity is } 150-160 \mathrm{~dB} \text { and the frequency is } 1-2 \mathrm{kHz} \text {. }\end{array}$ \\
\hline 1993 & Hoffman[10] & $\begin{array}{l}\text { studied the dual-mode agglomeration of the coal fly ash with a frequency of } 44 \mathrm{~Hz} \text {, and the sound pressure } \\
\text { level of } 160 \mathrm{~dB} \text {, and also adding large limestone particles, whose particle size is } 88 \mu \mathrm{m} \text {. The experimental } \\
\text { results showed that the acoustic agglomeration efficiency is improved after the addition of limestone } \\
\text { particles. }\end{array}$ \\
\hline 1993 & Hoffman[11] & the mass fraction of $d p>11 \mathrm{~m}$ after agglomeration is significantly improved at high temperature \\
\hline 2003 & $\begin{array}{l}\text { Southeast } \\
\text { University[12] }\end{array}$ & the effect of the combined action of acoustic and atomizing water is the best \\
\hline 2006 & Yao Gang[13] & $\begin{array}{l}\text { according to the theory of standing wave sound fields and studied dynamic characteristic of fine particles } \\
\text { and the overall removal effect from perspectives of microscopic and microscopict }\end{array}$ \\
\hline 2007 & Riera-Franco [14] & $\begin{array}{l}\text { use the sound source of } 20 \mathrm{kHz} \text {, and increase } 6 \% \text { of reunion indoor humidity can make the acoustic } \\
\text { agglomeration efficiency submicron particles increases from } 25 \% \text { to } 56 \% \text {. }\end{array}$ \\
\hline 2010 & $\begin{array}{l}\text { Zhang } \\
\text { Guangxue[15] }\end{array}$ & $\begin{array}{l}\text { studies on the acoustic agglomeration mechanism of coal-fired fly ash, agglomeration mechanism as well } \\
\text { as numerical simulation by adopting the source system of high and low frequency }\end{array}$ \\
\hline 2012 & Wang Jie[16] & Study the flying fine ash particles removal by the means of acoustic joint to lime seed particles and spray \\
\hline
\end{tabular}

The research of acoustic agglomeration has been still in the experimental stage without 
industrial property. There are two reasons as follows. Firstly, the existing research have been mainly on the macroscopic properties of the operating parameters of acoustic agglomeration, lacking the deep theoretical exploration. Synthetic mechanism, the most significant one in the acoustic agglomeration, has not been tested, which restricted the further development of the technology. Secondly, the lack of appropriate sound source operating under the environment of high temperature and full of frog and dust as well as high energy consumption count against the development of the acoustic agglomeration. Accordingly, scholars put forward ways to combine seed particles to acoustic agglomeration.

\section{Ultrasonic atomization combined with acoustic agglomeration}

\section{The principle of ultrasonic atomization}

Ultrasonic atomization is the use of ultrasonic wave to make water into small particles water mist, because ultrasound has a good direction, reflectivity and penetration ability, can spread in the gas, liquid and solid media to produce a variety of ultrasonic effect, in which the main role of water atomized is mechanical effects, thermal effects, and acoustic cavitation [17].

Mechanical effect is mainly because of the ultrasonic wave in propagation process can cause particle vibration, and this vibration will have an impact inside of the liquid, destroying the force between liquid molecules; thermal effect is because ultrasound has a high energy, in through the water molecules will produce friction and transform the sound energy into heat energy, for the destruction of intermolecular forces provide energy; acoustic capitation is the acoustic wave propagation in a liquid, it will generate pressure fluctuation, and appear the negative pressure phenomenon of lower than the static pressure. In the negative pressure region of the liquid, the structural defects (nucleation) of the liquid will gradually grow, become visible to the naked eye can be formed until bubbles burst microns, which is acoustic cavitation.

\section{The advantages of ultrasonic atomization}

(1)The traditional wet dust removal technology produces lager droplets, and most of them are large than $200 \mu \mathrm{m}$, so many of the submicron level of respiratory dust is not very good to be intercepted and captured and then directly discharged into the atmosphere, leading to its removal efficiency was only about $35 \%$, so its effect is not ideal. The ultrasonic atomization dust removal technology can solve the above problems, and most of the droplets whose size is about $10 \mu \mathrm{m}$, and the collection efficiency of the respiratory dust can be increased from $35 \%$ to $80 \%$ after use the ultrasonic atomization technology.

(2)The water consumption is saved, and the water consumption of ultrasonic atomization is greatly reduced, which is only $0.1 \%$ of the traditional wet dust removal and even smaller. Because of good atomization effect, the utilization rate of water is greatly improved. At the same time, the need to deal with the amount of drainage is less, and the subsequent impact on the environment is small.

(3)The subsequent processing. Due to the use of less water, the dust in the trap is similar to the "mud cake", so the subsequent processing equipment is simple and easy to handle and transport.

\section{Ultrasonic atomization combined with acoustic agglomeration}

Based on the above advantages of ultrasonic atomization, the method of ultrasonic atomization combined with acoustic agglomeration is proposed to remove PM2.5. There are studies show that, compared with the conventional spray methods, the size of the droplets produced by ultrasonic 
atomization is similar to the inhaled fine particles, so it's more easily to capture the dust, and the trap efficiency can greatly improve. Therefore, ultrasonic atomization combined with acoustic agglomeration not only improves the adverse of the traditional atomizing device, but also retained the advantage of the combination of ultrasonic atomization and acoustic agglomeration can improve the efficiency of collision between particles, thus can improve the removal efficiency of ultrafine particles. The combined system (Fig.1) should add a set of atomization on the basis of acoustic agglomeration [18].

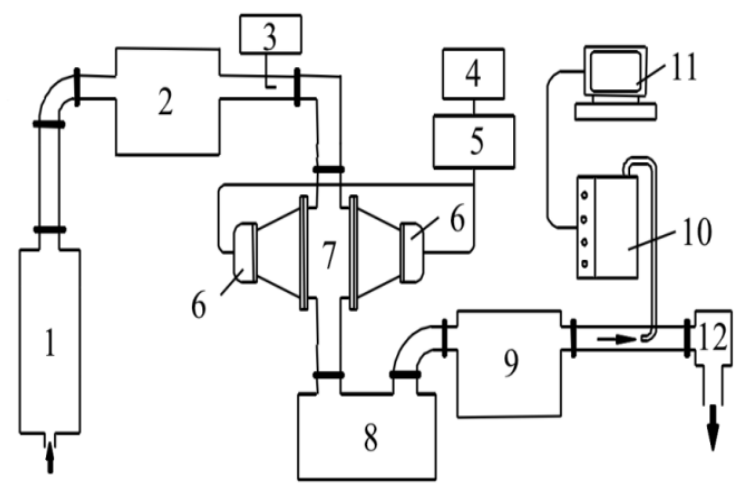

Fig.1 Schematic diagram of acoustic agglomeration combined with spray [18]
1. Aerosol generator
2. Buffer chamber
3. Spray jet
4. Signal generator
5. power amplifier
6. Sound source
7. agglomeration chamber
8. The first removal chamber
9. The second removal chamber
10. ELPI
11. PC
12. Blower

\section{Conclusions}

Although the development of acoustic agglomeration technology has been a hundreds of years, but because of its high noise, high energy consumption, low efficiency and other problems, it has not been widely used in the industry. But adding seed particles can solve these problems in a certain extent, and the experimental results show that the effect of adding atomization water is the most obvious, and the water is atomized by an ultrasonic wave can produce a uniform particle and similar to the fine dust particle size, so its effect is more obvious than ordinary atomizing device. So in this paper, ultrasonic atomization is applied in the process of acoustic agglomeration, which can effectively improve the trapping and settling efficiency of ultrafine particles, and this method also provides a new way for the study of acoustic agglomeration in the future.

\section{Reference}

[1]Danser H W,Neumann E P.Industrial sonic agglomeration and collection system [J].Industrial and Engineering Chemistry,1949,41(11):2439-2442.

[2]Mednikov E P. Acoustic coagulation and precipitation of aerosols [M] Translated from Russian Consultants Bureau, 1965.

[3] Chen Jun. ultrafine particles of coal-fired spray agglomeration model [J], Journal of coal.2005,30: 623-636.

[4] Wei Feng. Simulation study of agglomeration of ultrafine particles of coal combustion [J], engineering thermal physics journal, 2005, 26:15-518. 
[5]I. Gonzalez, J. A. Gallego-Juarez. E. Riera, The influence of entrainment on acoustically induced interactions between aerosol particles — an experimental study [J], Journal of Aerosol Science. 2003. 34: 1611-1631.

[6]E. Riera-Franco de Sarabia, L. Elvira-Segura, I. Gonzalez-Gomeza, J. J.Rodnguez-Marotob, R. Munoz-Bueno, J. L. Dorronsoro-Areal, Investigation of theinfluence of humidity on the ultrasonic agglomeration of submicron particles in dieselexhausts [J], Ultrasonics, 2003, 41: 277-281.

[7]Rajendran N, Wegrzyn J, Cheng M T, Shaw D T. Acoustic precipitation of aerosol understanding-wave condition. Journal of Aerosol Science, 1979, 10(3):329-338.

[8]M. T. Cheng, P. S. Lee, A. Berner, D. T. Shaw, Orthokinetic agglomeration in an intense acoustic field[J],Journal of Colloid and Interface Science. 1983, 91: 176-187.

[9]Tiwary R, Reethof G. Numerical simulation of acoustic agglomeration and experimental verification[J].Transaction of the ASME, 1987, 109:185-191.

[10]T. L. Hoffmann, W. Chen, G H. Koopmann, A. W. Scaroni, L. Song, Experimental and Numerical-analysis of Bimodal Acoustic Agglomeration[J], Journal of Vibration and Acoustics-Transactions of the Asme, 1993, 115; 232-240.

[11]Hoffmann T L, Chen W, Koopmann G H, Scaroni A W, Song L. Experimental and numerical analysis of bimodal acoustic agglomeration. Transactions of the ASME, 1993, 115(3):232-240.

[12]I. Gonzalez, J. A. Gallego-Juarez. E. Riera, The influence of entrainment on acoustically induced interactions between aerosol particles — an experimental study [J], Journal of Aerosol Science. 2003, 34: 1611-1631.

[13] Yao Gang. Coal Combustion Inhalable Particulate Matter acoustic agglomeration -microscopic and macroscopic dynamics visualization and simulation results Experimental Study [D]. Southeast University in 2006.

[14] Zhao Bing, Chen Houtao, Xu Jin, Shen Xianglin. Experimental study on the removal of fine particles by acoustic combined with seed particles [J]. Power engineering, 2007, 27 (5): 785-788.

[15]Zhang Guangxue. Theoretical and experimental studies on acoustic agglomeration of coal fired fly ash aerosol. Zhejiang University [D].2010.

[16] Wang Jie, Study on acoustic agglomeration combined with other methods to remove particles from coal combustion fly ash [D]. Zhejiang University. 2012.

[17] Chen Zhuokai. Study on the mechanism and the application of the ultrasonic atomizing water mist mechanism and its application in the experiment: Guangzhou: Guangdong University of Technology, 2007.

[18]Chen Houtao, Zhao Bing, Zhang Ruxin, et al. Experimental Study on the Enhancement of Removing PM2.5 in Coal-fired Fumes Under the Combined Effect of Acoustic Wave and Atomized Water Drop [J]. Proceedings of the CSEE, 2009, 35-40.

[19] Yang Linjun, Zhao Bing, Yao Gang, Shen Xianglin. Research progress and Prospect of acoustic agglomeration of particulate matter in combustion, 2007, 5 (13): 41-45.

[20] Wei Feng, Zhang Jun, Wang Chunmei, Zheng Chuguang. Research progress of coal combustion ultrafine particle agglomeration promoting technology $[\mathrm{J}]$. coal conversion, 2003, 26 (3): $27-31$.

[21] Hou Tao Chen, Zhao Bing, Zhang Ruxin, Cao Jinxiang, Shen Xianglin. Experimental study on the combined effect of acoustic wave and atomized water drop to enhance the removal of coal-fired PM2.5 [J]. The Chinese Journal of mechanical and electrical engineering, 2009, 29 (2): 35-40.

[22] Geng Jianxin, Wang Liping, Wang Rui, Wang Zhexiao. Preliminary study on the classification of coagulation of particles. Comprehensive utilization of resources in China [J], 2008, 26 (5): 35-37. [23] Yang Linjun, Huang Yonggang, Shen Xianglin. Progress in the development of acoustic 
agglomeration technology $[\mathrm{J}]$, clean coal combustion and power generation technology, 2008, 6:9-12.

[24] Chen Houtao, Zhao Bing, Xu Jin, Shen Xianglin. Experimental research on the removal of acoustic agglomeration of ultrafine particles from coal combustion fly ash [J]. Chinese Journal of electrical engineering, 2007, 27 (35): 28-32.

[25] Li Hailong, Zhang Junying, Zhao Yongchun, Yang Yan, Zheng Chuguang. Experimental study on solid liquid agglomeration of coal fired fine particles [J]. Chinese Journal of electrical engineering, 2009, 29 (29): 62-66.

[27]Gonzalez-Gomez I, Hoffmann T L, Gallego-Juarez J A .Theory and calculation of sound induced particle interactions of viscous origin. Acta Acustica, 2000, 86(5):784-797.

[28]Gonzalez T, Hoffmann T L, Gallego J A. Visualization of hydrodynamic particle interactions:validation of a numerical model. Acta Acustica, 2002,88(1):19-26.

[29]Gonzalez I, Gallego J A, Riera E. The influence of entrainment on acoustically induced interactions between aerosol particles and experimental study. Journal of Aerosol Science, 2003, 34(12):1611-1631.

[30]Sergey V, Yamamoto T. Acoustically controlled behavior of dust particles in high temperature gas atmosphere, ISIJ International, 2004, 44(2):275-284.

[31]Sarabia E R F, Elvira L, et al. Investigation of the influence of humidity on the ultrasonic agglomeration of submicron particles in diesel exhausts. Ultrsonics, 2003, 41(4):277-281. 